\title{
Unilateral Nasal Obstruction by Respiratory Epithelial Adenomatoid
}

\section{Hamartoma}

\section{Sophie Mikkelsen $^{1 *} \mid$ Kasra Zainali-Gill ${ }^{2}$}

*Correspondence: Sophie Mikkelsen

Address: ${ }^{1}$ Specialist registrar, Department of Oto-Rhino-Laryngology, Region Hospital West Jutland, Holstebro, Denmark; ${ }^{2}$ Senior registrar, Department of Oto-Rhino-Laryngology, Region Hospital West Jutland, Holstebro, Denmark e-mail $\bowtie$ : sopmik@rm.dk

Received: 05 July 2020; Accepted: 22 July 2020

Copyright: (C) 2020 Mikkelsen S. This is an open-access article distributed under the terms of the Creative Commons Attribution License, which permits unrestricted use, distribution, and reproduction in any medium, provided that the original work is properly cited.

\section{ABSTRACT}

Respiratory epithelial adenomatoid hamartoma is a rare benign tumour involving the nasal cavity, paranasal sinuses or rhinopharynx. The tumour most often arises from the posterior part of the nasal septum.

We report a case of nasal obstruction throughout a 25-30 year period in a 74-year-old woman caused by a respiratory epithelial adenomatoid hamartoma originating from the uncinate process. The tumour was surgically excised whereby dramatically improving air passage through the nose.

Biopsies from pathologies in the nasal cavity is important to get a definite diagnosis and distinguish benign from malignant tumours. A biopsy verified diagnosis of REAH is important prior to plan the extent of surgical excision of this benign lesion to avoid unnecessary aggressive surgery and associated complications such as anosmia, orbital or skull base trauma with risk of orbital haematoma, blindness, cerebrospinal fluid leak and meningitis.

Keywords: Respiratory Epithelial Adenomatoid Hamartoma, REAH, One-Sided Nasal Obstruction, Benign Nasal Tumour

\section{Introduction}

Respiratory epithelial adenomatoid hamartoma (REAH) is a rare benign tumour involving the nasal cavity, paranasal sinuses or the rhinopharynx (Saraniti et al., 2018; Gauchotte et al., 2013; Kessler and Unterman, 2004; Goh et al., 2018).

Approximately $70 \%$ of the tumours are found in the nasal cavity (Kessler and Unterman, 2004; Saniasiaya et al., 2017), most often derived from the posterior part of the nasal septum (Gauchotte et al., 2013; Kessler and Unterman, 2004; Saniasiaya et al., 2017; Rom et al., 2018; Bignami et al., 2014).

The diagnosis was first described in 1995 by Wenig and Heffner (Saraniti et al., 2018; Gauchotte et al., 2013; Kessler and Unterman, 2004; Goh et al., 2018; Saniasiaya et al., 2017; Rom et al., 2018; Bignami et al., 2014; Al Hawat et al., 2015; Safi et al., 2019) and was introduced in the WHO 
classification of tumours of the head and neck in 2005 (Bignami et al., 2014; Safi et al., 2019).

The aetiology remains unknown (Saraniti et al., 2018; Kessler and Unterman, 2004; Saniasiaya et al., 2017; Rom et al., 2018; Bignami et al., 2014; Al Hawat et al., 2015; Safi et al., 2019), but inflammation is thought to contribute to the development of REAH (Kessler and Unterman, 2004; Saniasiaya et al., 2017; Rom et al., 2018).

Most cases of REAH occur in adult patients in the 5th or 6th decade of life (Gauchotte et al., 2013; Kessler and Unterman, 2004) with male predominance (Saraniti et al., 2018; Gauchotte et al., 2013; Kessler and Unterman, 2004; Goh et al., 2018; Saniasiaya et al., 2017; Rom et al., 2018; Bignami et al., 2014; Al Hawat et al., 2015). The symptoms are sparse and diffuse (Saraniti et al., 2018; Kessler and Unterman, 2004; Saniasiaya et al., 2017; Bignami et al., 2014), and typically include one or more of the following: nasal obstruction, recurrent rhinosinusitis, epistaxis, hyposmia, or headache (Gauchotte et al., 2013; Kessler and Unterman, 2004; Goh et al., 2018; Rom et al., 2018; Bignami et al., 2014; Al Hawat et al., 2015).

The tumour is most often unilateral and described as a grey or white polypoid mass on clinical examination, much like an inflammatory sinonasal polyp (Kessler and Unterman, 2004). Histology shows distinct characteristics with the proliferation of cyst like epithelial structures surrounded by a ciliated respiratory epithelium (Kessler and Unterman, 2004).

Complete local resection of the tumour is the treatment of choice (Saraniti et al., 2018; Kessler and Unterman, 2004; Goh et al., 2018; Saniasiaya et al., 2017). Recurrence after complete resection is very rare (Gauchotte et al., 2013; Goh et al., 2018; Rom et al., 2018).

\section{Case Report}

A 74-year-old woman was referred to the Department of Oto-Rhino-Laryngology, Region Hospital West Jutland, Denmark, due to a thyroid adenoma. Inspection of the left nasal cavity revealed a polypoid tumour. The patient reported that she had suffered from left-sided nasal obstruction throughout 25-30 years. The obstruction evolved after extraction of a tooth in the left side followed by sinusitis of the left maxillary sinus. During the years, she had had signs of left-sided sinusitis a few times, but generally experienced no pain, purulent secretion or bleeding from the nose. The patient felt left-sided pressure of the face from time to time.

The patient was in good general health but was diagnosed with multiple adenomas of the thyroid gland, mild aorta insufficiency, and polyarthrosis of the wrist and fingers. She had always been a non- 
smoker.

Four years earlier, a piece of tissue was extruded during nose blowing which her general practitioner interpreted as an inflammatory nasal polyp by looks. No further examination was performed.

On clinical examination, the nose deviated slightly to the left and the nasal septum was heavily deviating to the right. A soft, polypoid tumour filled most of the left nasal cavity. The tumour was movable and seemed to adhere to the lateral wall around the middle concha and middle meatus. The mucosa was smooth and intact. The rhinopharynx was free of tumour tissue.

A CAT-scan of the nose and sinuses showed a large lobulated soft tissue tumour involving the left inferior and middle meatus in addition to the inferior concha and to some extent the middle concha. The tumour measured $2.8 \mathrm{~cm} \times 2.3 \mathrm{~cm} \times 5.2 \mathrm{~cm}$. There was no bone destruction, and the sinuses were normally pneumatized.

At endoscopic surgery, the tumour was found to originate from the top of the uncinate process via a thin stalk. There were no adherences to the nasal septum. There was minimal per-operative bleeding, but the patient experienced bleeding 2.5 hours after surgery. She was taken to theatre and the bleeding was controlled by diathermy. A NasoPore was placed around the uncinate process to ensure haemostasis.
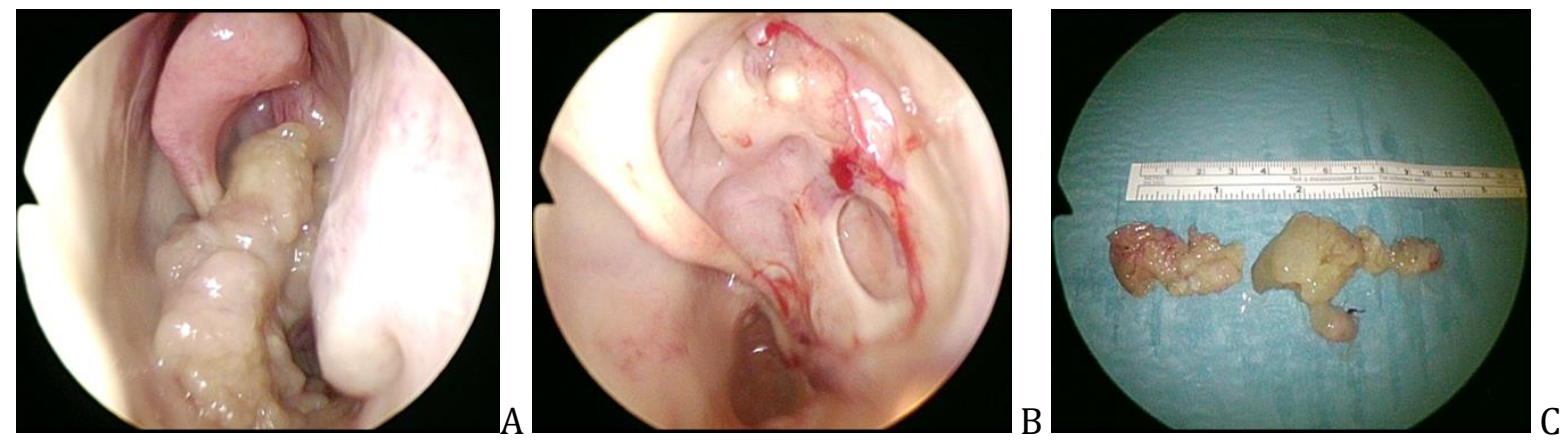

Figure 1: (A) Endoscopic picture of the tumour in the left nasal cavity. (B) Endoscopic picture of the nasal cavity after surgical excision of the tumour. (C) The tumour tissue after excision

Histological examination showed a polypoid and oedematous tissue with a hyperplastic pseudostratified ciliated columnar epithelium with goblet cells. There was intraepithelial inflammation with neutrophil granulocytes. In the underlying stroma, there were cystic dilated hyperplastic glands frequently in direct continuity with the mucosal surface. There were no signs of dysplasia or malignancy. 
Due to cutting phenomena, a few areas had micro focal lesions that had similarities with Schneiderian papilloma, but all areas had a hyperplastic pseudostratified columnar epithelium.

The histology report was consistent with REAH.

At follow up 25 days after surgery, the patient had no symptoms from the nose. The passage of air through the nose was dramatically improved.

\section{Discussion}

We present a patient with single sided nasal obstruction for more than 25 years.

Unilateral nasal obstruction ought to be examined by an oto-rhino-laryngologist in order to visualize the nasal cavity and to obtain diagnostic biopsies.

It can be difficult to distinguish REAH from other nasal tumours, such as Schneiderian papilloma, inflammatory polyps, or sinonasal adenocarcinoma, on clinical examination and imaging alone (Gauchotte et al., 2013; Kessler and Unterman, 2004; Goh et al., 2018; Safi et al., 2019). Biopsies are mandatory in order to differentiate between REAH and other benign or malignant tumours, and to plan the extent of surgical treatment.

Bignami, et al. (2014) presented a retrospective analyses of 27 patients. Seventeen were diagnosed preoperatively with REAH and underwent extensive surgery with subperiosteal dissection and drilling of the underlying bone. The remaining ten patients were diagnosed with REAH postoperatively after endoscopic sinus surgery, without extended surgery, for presumed nasal polyposis. No recurrences developed in any of the 27 patients throughout the follow-up of 12 to 126 (mean 61.2) months. The findings suggest that REAH can be treated with less aggressive surgery without risk of recurrence as well as surgical complications.

\section{Conclusion}

Patients with unilateral nasal obstruction should be referred to an oto-rhino-laryngologist for examination of the nose and biopsies of any pathology. A biopsy verified diagnosis of REAH is important prior to planning the extent of surgical excision of this benign lesion to avoid unnecessary aggressive surgery and associated complications such as anosmia, orbital or skull base trauma with risk of orbital haematoma, blindness, cerebrospinal fluid leak and meningitis. 


\section{References}

Al Hawat A, Mouchon E, De Bonnecaze G, Vergez S, Serrano E. Our experience with respiratory epithelial adenomatoid hamartomas of the olfactory cleft. Eur Arch Otorhinolaryngol 2015; 272: 2867-2870.

Bignami M, Volpi L, Karligkiotis A, De Bernardi F, Pistochini A, AlQahtani A, Meloni F, Verillaud B, Herman P, Castelnuovo P. Endoscopic endonasal resection of respiratory epithelial adenomatoid hamartomas of the sinonasal tract. Int Forum Allergy Rhinol 2014; 4: 961-965.

Gauchotte G, Marie B, Gallet P, Nguyen DT, Grandhaye M, Jankowski R, Vignaud JM. Respiratory epithelial adenomatoid hamartoma: a poorly recognized entity with mast cell recruitment and frequently associated with nasal polyposis. Am J Surg Pathol 2013; 37: 1678-1685.

Goh L-C, Wan M-H, Shashi G, Elangkumaran S. Lateral Nasal Wall Respiratory Epithelial Adenomatoid Hamartoma (REAH): A Diagnostic Conundrum. Iranian journal of otorhinolaryngology 2018; 30: 225-229.

Kessler HP and Unterman B. Respiratory epithelial adenomatoid hamartoma of the maxillary sinus presenting as a periapical radiolucency: a case report and review of the literature. Oral Surg Oral Med Oral Pathol Oral Radiol Endod 2004; 97:607-12.

Rom D, Lee M, Chandraratnam E, Chin R, Sritharan N. Respiratory Epithelial Adenomatoid Hamartoma: An Important Differential of Sinonasal Masses. Cureus 2018; 10: e2495.

Safi C, Li C, Tabaee A, Ramakrishna R, Riley CA. Outcomes and imaging findings of respiratory epithelial adenomatoid hamartoma: A systematic review. Int Forum Allergy Rhinol 2019; 9: 674-680.

Saniasiaya J, Md Shukri N, Ramli RR, Wan Abdul Wahab WNN, Zawawi N. Sinonasal respiratory epithelial adenomatoid hamartoma: An overlooked entity. Egypt J Ear, Nose, Throat Allied Sci 2017; 18: 191-193.

Saraniti C, Gallina S, Santangelo M, Montana F, Portelli F, Orlando E. Sinonasal respiratory epithelial adenomatoid hamartoma: A report on three cases. Euro Mediterranean Biomed J 2018; 13: 60-64. 